\title{
A MISE-EN-SCĖNE NO CINEMA DOS ANOS 60 E SUA RELAÇÃO COM A VITRINE DE MODA
}

\author{
Lilian Daros Pescador ${ }^{1}$
}

\section{INTRODUÇÃO}

A moda e o cinema possuem relações profícuas e complementares entre si. Sabendo disso, buscamos entender, mapear e investigar elementos específicos da linguagem de construção de vitrines de moda e suas relações com a mise-enscène do cinema dos anos 60 . Encontramos vários pontos convergentes entre a mise-en-scène e a vitrine de moda. Mostramos, assim, as semelhanças, familiaridades, proximidades e entrelaçamentos que estabelecem esses assuntos, entre os quais podemos citar como parte fundamental dessas duas categorias o enquadramento, uma vez que, assim como na mise-en-scène, a vitrine é como uma caixa onde os elementos "cênicos" são colocados, de modo a fazer com que as pessoas se sintam atraídas a visualizar seu conteúdo. Dessa forma, também acontece no cinema, em que os espectadores são fascinados pelo ecrã. Ancoramos essa pesquisa com autores como Benjamin (2009), que nos aponta o surgimento da moda como imagem e o ato de flânerie; Bordwell e Thompson (2013), com o conceito de mise-en-scène e enquadramento e Silvia Demetresco com seus estudos sobre vitrina.

Como parte da metodologia e para dar sustentação às relações a serem investigadas, foram feitos visionamentos de filmes europeus e brasileiros, dos quais podemos citar alguns como: Acossado, diretor Jean-Luc Godard, 1960; A Mulher de Todos, diretor Rogério Sgarzerla, 1969; A Noite, diretor Michelangelo Antonioni, 1961; A Aventura, também do diretor Antonioni, 1960; Cléo das 5 às 7, diretor Agnès Varda, 1962; Deserto Vermelho, diretor Antonioni, 1964; Fome de Amor, diretor Nelson Pereira dos Santos, 1968; Matou a Família e Foi ao Cinema, diretor Júlio Bressanem, 1969; Noite Vazia, diretor Walter Hugo Khouri, 1964; O Bandido da Luz Vermelha, também do diretor Rogério Sgarzerla, 1968; O Eclipse, diretor Antonioni, 1962; São Paulo S/A, diretor Glauber Rocha, 1967; Viver a Vida, também do diretor

\footnotetext{
${ }^{1}$ Instituto Federal de Santa Catarina. lilian@ifsc.edu.br
} 
Jean-Luc Godard, 1962; O Ano Passado em Marienbad, diretor Alain Resnais, 1961; Modesty Blaise, do diretor Joseph Losey, 1966; Blow up, diretor Antonioni, 1966; Georgy Girl do diretor Silvio Narizzano, 1966 e Poor Cow de Ken Loach, 1967. Após o visionamento desses filmes, foi realizado o congelamento de alguns frames que possuíam relação com a moda e a vitrine.

Este artigo empregou a abordagem qualitativa, foram consideradas especificidades que o objeto de estudo requer em sua análise. Também buscamos conhecimento teórico através de livros de filosofia, moda e cinema. Foram utilizadas referências recentes, pesquisados no ambiente virtual para caracterizar 0 atual entendimento que envolve o objeto.

Entendemos, nesse sentido, o cinema e a moda como manifestações culturais que convergem em uma perspectiva interdisciplinar, focada nos modos como a mise-en-scène se constrói a partir de elementos que também constituem o universo da moda: a vitrine. Essa perspectiva privilegia um olhar que foge à noção de pureza das formas de arte e de manifestações culturais.

A palavra mise-en-scène, oriunda do teatro e incorporada ao cinema, foi o suporte das relações propositadas com a moda. Ao estabelecer analogias entre a mise-en-scène do cinema com filmes europeus e brasileiros dos anos 60 , com as vitrines de moda.

Para tanto, ancoramo-nos no estudo de Walter Benjamin (2009). Nele, encontramos indícios de que a moda se torna imagem quando os sujeitos passam a consumir a sua imagem. Nesse sentido, verificamos que isso ocorre desde a passagem do século XIX para o século XX, com o crescimento do capitalismo e o conhecimento dos processos de modernização. Nesse contexto, surgiram vitrines, galerias e ato de flânerie. Nesse momento, cabe destacar que um passo fundamental nessa pesquisa foi o reconhecimento das transformações e rupturas que marcaram a passagem do século XIX para o século XX, momento em que a consolidação do capitalismo passa a estimular o consumo não só de produtos, mas de imagens, sejam nas vitrines das galerias, fotografias, cartazes, panfletos etc. É nesse contexto, afinal, que as vitrines de moda podem ser vistas como "enquadramentos", ou seja, pela semelhança que há entre a organização de manequins e a disposição de atores/atrizes em um quadro de cinema, oferecidos ao olhar de passantes (flâneurs, entre outros). 
Dando continuidade ao aporte teórico, desenvolvemos o conceito de mise-en-scène, debruçando-nos sobre o estudo de David Bordwell e Kristin Thompson (2013), que a define como tudo aquilo que é posto em frente à câmera para ser filmado. Após, levantamos alguns encadeamentos desse conceito, como noções sobre o enquadramento e sobre os elementos colocados em cena, como a disposição do cenário, a iluminação, os personagens, os objetos em cena, o figurino e a maquiagem.

Em suma, esse estudo possibilitou perceber que são muitos os pontos relacionáveis entre cinema e moda, uma vez que muitos conceitos e linguagens do cinema e da mise-en-scène também foram incorporados pelas vitrines, a saber: o cenário, a iluminação, os objetos expostos, os personagens/manequim, o figurino/vestimenta, a encenação, a tela ecrã/vidraça, o artista de composição, o diretor de arte e o fotógrafo de cena/vitrinista. Além do mais, ao analisar o cinema dos anos 60, deparamo-nos com as perambulações, que são os passeios sem sentido ao contexto fílmico uma característica das obras/filmes de Antonioni e as comparamos com os flâneurs, que vivem em um tempo diferente do real e que passeiam nas ruas olhando as vitrines, contemplado sua imagem, fazendo coisas sem importância. Os filmes de Antonioni, assim como de outros diretores do cinema dos anos 60, apresentavam andanças, sem diálogo, como se as perambulações fossem utilizadas para aumentar o tempo fílmico. No caso das vitrines, conforme Demetresco (2001, p. 74), "a vitrina torna-se um discurso com varias versões ao mesmo tempo, sendo todas válidas por traduzir diferentes efeitos de sentido"; e uma variação em conformidade com as perambulações do cinema é a questão de flanar, que Benjamim (2009) descreve como o ato de flânerie, sendo o passeio sem preocupações, no qual o sujeito com um olhar ocioso passeia pelas vitrines. Nessa perspectiva, segundo Demetresco (2001), a vitrine é rejeitada como um instrumento de venda material. Assim, podemos dizer que há uma "venda" apenas imagética. Melhor dizendo, as pessoas que apenas observam a vitrine, na verdade, "compram" a imagem projetada por ela. Dessa forma, voltando ao ponto que trouxe essa discussão, também podemos dizer que o perambular no cinema é a compra de uma imagem projetada pela tela.

No que se refere aos filmes analisados, em vários deles foram descobertas superfícies especulares nas mise-en-scènes, que possuem afinidades 
com as vitrines de moda. Essa analogia foi possível pelo fato de o vidro da vitrine refletir tudo a sua volta e, consequentemente, refletir o sujeito que a observa.

Nesse contexto, Cléo das 5 às 7, dirigido por Agnès Varda, em 1962, foi o filme em que mais apareceram essas imagens refletidas. A título de exemplo, em determinada parte do filme, a personagem principal vai às compras e ela experimenta vários chapéus, logo, as cenas evidenciam imagens dela se olhando no espelho. De acordo com Benjamin (2009, p. 579), "Paris é a cidade dos espelhos. [...] Aqui as mulheres se vêem a si mesmas mais do que em outros lugares, daí surgiu a beleza singular das parisienses. Antes que um homem olhe para elas, já terão visto, elas mesmas, sua imagem refletida por dez vezes". Dessa forma, podemos dizer que Cléo é a imagem da mulher flanando, ela é a flâneuse. A sua imagem é tão importante para ela quanto para o filme, por isso há tantas imagens suas olhando para o espelho.

No entanto, a representação mais importante é a do sujeito observador, que vê refletida a sua própria imagem no vidro da vitrina em meio às outras imagens na multidão. Conforme Bigal (2001, p. 9),

Pois é interessante notar que a pragmática fundada no reflexo da vidraça não promove apenas objetos de consumo, mas também ampliam, de maneira imensurável, os momentos de subjetividade do usuário, convidando-o a uma fantástica viagem do espaço ao tempo, da luz à sombra, da forma à deformidade, do exterior ao interior e o inverso, proporcionalmente.

Nesse sentido, a vitrine, como já mencionado anteriormente, é um entre lugar, pois ela mostra o que está dentro e reflete o que está fora. Podemos dizer, então, que o vidro ou a vidraça é uma linha tênue de fronteiras: às vezes, é o sujeito refletido que olha a vitrina e, outras vezes, é a vitrina que olha o observador, como uma janela que está sempre aberta a todos os olhares. Assim, conforme Demetresco (2001, p. 78), a "vitrina apresenta a imagem e reflete-a, não só no sonho, no imaginário, mas também na realidade. Todos os passantes a usam como espelho ou a admiram com curiosidade. As imagens se fundem, o sonho e o real resultam numa terceira imagem - o reflexo da imagem real (espelhada no vidro)". É justamente nesse contexto que as imagens especulares do cinema moderno podem ser comparadas ao reflexo causado pela vidraça da vitrina como uma encenação do real, uma visão de mundo do sujeito defronte ao espelho. E, ressaltamos, é o olhar subjetivo de cada um que sacraliza esse fato. No caso da mise-en-scène do cinema, 
podemos dizer que esse olhar pode ser o olho do diretor, que terceiriza o olhar no espelho e mostra somente o que o seu enquadramento visual permite apresentar.

Cabe enfatizar que as imagens que são projetas nos reflexos são de personagens femininas, e essas imagens de mulheres fazem com que elas sejam praticamente incorporadas ao que é a mise-en-scène da vitrine. Nesse caso, há uma espécie de fusão do olhar, de quem é, ao mesmo tempo, o sujeito do olhar e o objeto do olhar, por que ela passa a fazer parte da vitrine. Assim, concomitantemente, é uma produtora da imagem e uma consumidora, que não apenas consome a imagem, mas a moda que está na vitrine. Logo, torna-se interessante esse "jogo" do reflexo, pois ele consegue produzir várias voltas nessas mise-en-scènes. É uma visão de mundo na qual essa mulher que se vê refletida é "convocada" para dentro da imagem, mas, por estar fora, é o sujeito e o objeto do olhar, ou seja, produtora e consumidora de moda. $O$ entre lugar na verdade é o reflexo, porque se analisarmos o entre só surge quando se tem alguém de fora olhando. Nesse sentido, a vitrine através desse reflexo produz uma multiplicação dos papéis da mulher, pois ela é sujeito e objeto, é produtora e consumidora, é quem está olhando e é olhada ao mesmo tempo, uma vez que essa pessoa que está fora é incluída na imagem da vitrine. É pertinente dizer que a mulher não é literalmente colocada dentro da vitrine, pois ela não ultrapassa o vidro. Portanto, ela é colocada na vitrine como imagem.

Dessa forma, conseguimos estabelecemos relações e entrelaçamentos que compõe a textura da mise-en-scène do cinema dos anos 60 , aliás, do cinema como um todo, e das vitrines de moda. Consequentemente, os horizontes que norteiam os estudos sobre cinema e moda foram ampliados.

\section{RESULTADOS}

A palavra mise-en-scène, oriunda do teatro e incorporada ao cinema, foi o suporte das relações propositadas com a moda. Ao estabelecer analogias entre a mise-en-scène do cinema com filmes europeus e brasileiros dos anos 60 , com ensaios fotográficos de moda $e$ as vitrines verificamos, primeiramente, a necessidade de abordar o contexto histórico para entendermos em que momento a moda se torna imagem. 
Para tanto, ancoramo-nos no estudo de Walter Benjamin (2009). Desse modo, encontramos indícios de que a moda se torna imagem quando os sujeitos passam a consumir a sua imagem. Nesse sentido, verificamos que isso ocorre desde a passagem do século XIX para o século XX, com o crescimento do capitalismo e o conhecimento dos processos de modernização. Nesse contexto, surgiram vitrines, galerias e ato de flânerie.

Consequentemente, desenvolvemos o conceito de mise-en-scène, debruçando-nos sobre o estudo de David Bordwell e Kristin Thompson (2013), que a define como tudo aquilo que é posto em frente à câmera para ser filmado. Após, levantamos alguns encadeamentos desse conceito, como noções sobre o enquadramento e sobre os elementos colocados em cena, como a disposição do cenário, a iluminação, os personagens, os objetos em cena, o figurino e a maquiagem.

Amparados pelos estudos de Silvia Demetresco, desenvolvemos o conhecimento sobre a vitrine. Ademais, ao contextualizar a história da vitrine, recorremos também aos estudos de Benjamin (2009), que nos nortearam com a noção de vitrine como imagem, não de forma mercadológica, mas como um "consumo" das imagens vitrines.

Em suma, esse estudo possibilitou perceber que são muitos os pontos relacionáveis entre cinema e moda, uma vez que muitos conceitos e linguagens do cinema e da mise-en-scène também foram incorporados pelas vitrines, a saber: 0 cenário, a iluminação, os objetos expostos, os personagens/manequim, o figurino/vestimenta, a encenação, a tela ecrã/vidraça, o artista de composição, o diretor de arte e o fotógrafo de cena/vitrinista. Além do mais, ao analisar o cinema dos anos 60, deparamo-nos com as perambulações das obras/filmes de Antonioni e as comparamos com os flâneurs, que vivem em um tempo diferente do real e que passeiam nas ruas olhando as vitrines, contemplado sua imagem. No que se refere aos filmes analisados, em vários deles foram descobertas superfícies especulares nas mise-en-scènes, que possuem afinidades com as vitrines de moda. Essa analogia foi possível pelo fato de o vidro da vitrine refletir tudo a sua volta e, consequentemente, refletir o sujeito que a observa. Diante desses achados, chegamos à ideia de que a vitrine é um entre lugar, pois ela mostra o que há dentro do estabelecimento e, ao mesmo tempo, reflete o que está fora. Existindo nesses reflexos propostos pelas vitrines, uma espécie de fusão do olhar, produzindo várias 
voltas na mise-en-scène, pois nela existe uma visão de mundo onde a mulher que se vê refletida, ela é ao mesmo tempo "convocada" para dentro da imagem, mesmo estando fora dela. Dessa forma, ela é o sujeito e objeto do olhar, produtora e consumidora de moda.

Enfim, compreendemos que cinema e moda ganham mais entrelaçamentos e relações através da mise-en-scène do cinema e das vitrines. Além disso, acreditamos que esse estudo pode ser o ponto de partida para outras reflexões sobre o tema, bem como empregado em outros cinemas e períodos, de modo a ganhar novos olhares.

\section{REFERÊNCIAS}

BIGAL, Solange. Vitrina, do outro lado do visível. São Paulo: Nobel, 2001.

BENJAMIN, Walter. Passagens. BOLLE, Willi; MATOS, Olgária (Org.). Trad. Irene Aron; Cleonice Mourão. Belo Horizonte: Editora UFMG; São Paulo: Imprensa Oficial do Estado de São Paulo, 2009.

BORDWELL, David; THOMPSON, Kristin. A Arte do Cinema: Uma introdução. São Paulo: Editora da USP, 2013.

CLÉO das 5 às 7. Direção: Agnès Varda. Produção: Carlo Ponti. França, 1962. DEMETRESCO, Sylvia. Vitrina: teu nome é sedução. São Paulo: Pancrom, 1990. . Vitrinas em diálogos urbanos. São Paulo: Anhembi Morumbi, 2005. 